\title{
The Credible, The Creditable, The Creditworthy Healthcare System
}

\author{
Anubha Bajaj* \\ Deputy General Manager, LT Foods Ltd., India \\ *Corresponding author: Anubha Bajaj, Deputy General Manager, LT Foods Ltd, India \\ Submission: 漈 November 02, 2017; Published: 些 November 14, 2017
}

\section{Opinion}

The Government's goals \& objectives with the long term plans set out in the White paper by the Department of Health, titled "Equity \& Excellence Liberating the NHS" as released by the Secretary of State for Health Mr. Andrew Lansley are in entirety, concisely defining a "Patient Led NHS"

As envisioned, the professional will have more freedom of expression \& authority with clarity of vision in order to focus on improving the quality of services to the patient with a constant improvement in the health outcomes, while striving towards excellence. At the same instance, the services would be cost effective with best value for money.

Patients would be more informed so they can make effective, confident \& efficient choices, with appropriate guidance from the medical personnel - whatever platform they are dealing with.

The medical services would be more responsive to the patients who will be able to have more options in choosing the doctors they wish to deal with (though this should not lead to a negative/ unhealthy competition amongst co-professionals, we should all help each other grow professionally \& form close corroborative working relationships).

The value of comprehensive \& transparent information sharing with the patients, leading to them adopting healthier \& better choices, cannot be underrated.

As far as the changes in the Management protocols of the NHs are concerned-I'll leave the choices \& the decisions to my more senior colleagues with a direct experience of working with the NHs.

However the working of the professionals \& managers should be complimentary \& stress-free for effective implementation \& evolution of streamlined \& cost-effective services with no compromises on the quality- in fact working towards enhancing the same. 